\title{
An IPMSM Torque/Weight and Torque/Moment of Inertia Ratio Optimization
}

\author{
M. Caruso, A. O. Di Tommaso, R. Miceli, Member, IEEE, P. Ognibene, G. Ricco Galluzzo
}

\begin{abstract}
In this paper, a torque/weight and torque/moment of inertia ratio optimization procedure for interior permanent magnet syncronous motors (IPMSMs) is presented. More in detail, a performance comparison between several IPMSM rotor structures has been carried out in order to determine the optimum geometry that can maximize the torque/weight and torque/moment of inertia ratios. A commercial motor, with known electrical and mechanical characteristics, has been taken as reference. Its rotor structure has been modified several times, obtaining different rotor geometries and, therefore, many IPMSM models with different electrical and mechanical characteristics. The finite element method (FEM) analysis of each IPMSMs has been performed using the software FEMM, allowing to determine the related torque/load-angle characteristics. From the comparison between the torque/load-angle characteristics of the different IPMSM structures, it can be stated that significant performance improvements can be obtained in dependence not only of the type of permanent magnets and their direction of magnetization, but also of the PM displacement within the rotor.
\end{abstract}

Index Terms-IPMSM, permanent magnets, FEM analysis, optimization, torque/weight ratio, torque/moment of inertia ratio.

\section{INTRODUCTION}

$\mathbf{T}$ $\mathrm{HE}$ area of electrical machines has experienced a very significant innovation during the last three decades. This is due to the development of machines with new type of structures, materials and principle of operation. LIMs (Linear Induction Motors) [1], SPIMs (Single-phase Induction Motors) [2]-[5], micromotors [6], [7] and PMSMs (Permanent Magnets Syncronous Motors) [8], [9] are only few examples of this technological evolution. In comparison with the traditional type of machines, the performances achievable from these new type of electrical motors can be more suitable for specific applications, such as industrial and/or medical applications [10]-[12].

Interior Permanent Magnet Syncronous Motors (IPMSMs) are widely used in industrial drive applications, thanks to their great advantages [8], [9]. As a matter of fact, if compared with synchronous machines of the traditional type, higher

Massimo Caruso, Antonino Oscar Di Tommaso, Rosario Miceli and Giuseppe Ricco Galluzzo are with the Dipartimento di Energia, Ingegneria dell'informazione e modelli Matematici (DEIM) - Università degli Studi di Palermo, viale delle Scienze, Ed. 9, 90128 Palermo, Italy. e-mail: massimo.caruso16@unipa.it, antoninooscar.ditommaso@unipa.it, rosario.miceli@unipa.it, giuseppe.riccogalluzzo@unipa.it

Pietro Ognibene is with Terna S.P.A, Viale Egidio Galbani, 70 - 00156 Roma, Italy.

This work was financially supported by MIUR - Ministero dell'Istruzione dell'Università e della Ricerca (Italian Ministry of Education, University and Research), by PON04a2_H "i-NEXT" Italian research program and by SDESLab (Sustainable Development and Energy Saving Laboratory) of the University of Palermo. The Authors wish to thank all the SDESLab staff. efficiency, power factor, torque/weight and power/current ratios can be achieved. Moreover, since the excitation flux is generated by the permanent magnets (high energy $\mathrm{NeFeB}$ and SmCo magnets) located inside the rotor, the power losses are mainly produced on the stator and the motor does not need brushes for excitation current.

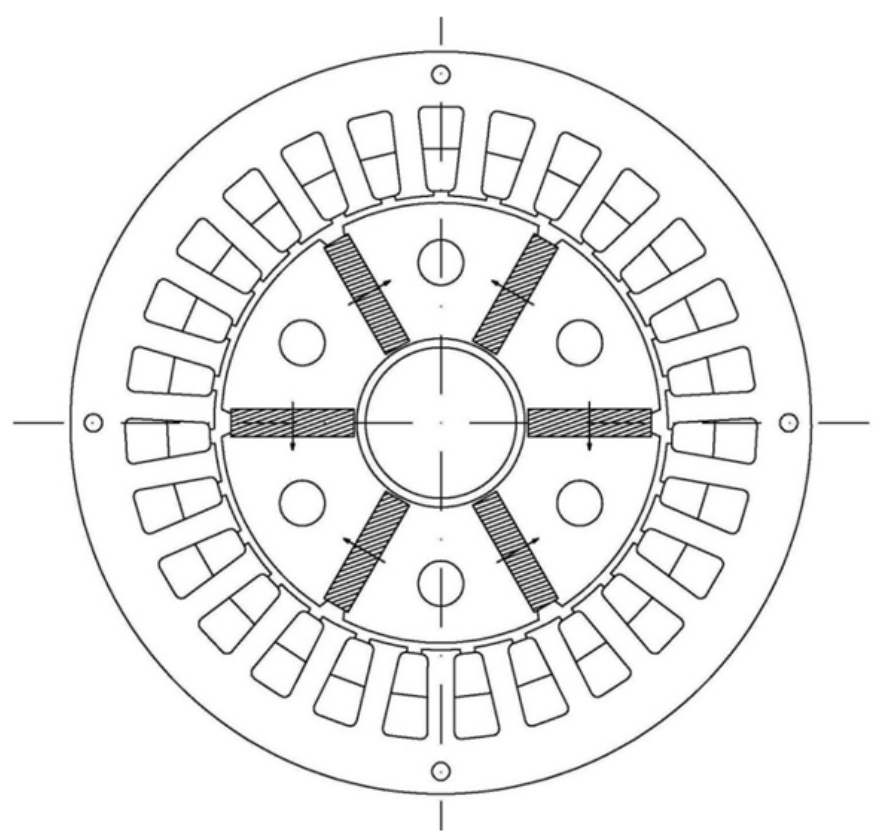

Figure 1. The A-type IPMSM cross-section.

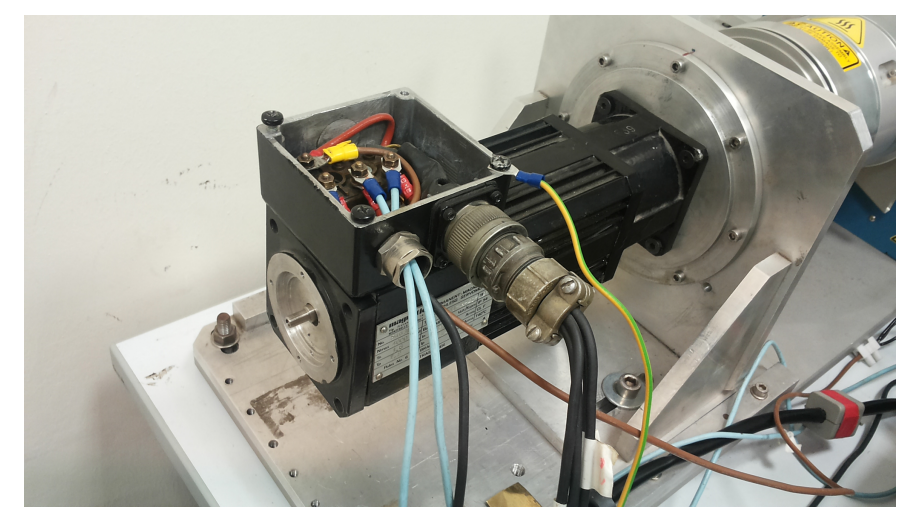

Figure 2. The A-type IPMSM machine.

Several IPMSM rotor structures are presented in literature [9]. In particular, many efforts have been carried out in the rotor design and in the magnet positioning within the rotor 
Table I

RATED VALUES OF THE A-TYPE IPMSM STRUCTURE.

\begin{tabular}{c||c} 
Quantity & Value \\
\hline \hline Voltage $[\mathrm{V}]$ & 132 \\
\hline Current $[\mathrm{A}]$ & 3.6 \\
\hline Speed [rpm] & 4000 \\
\hline Torque $[\mathrm{Nm}]$ & 1.8 \\
\hline Number of pole pairs & 3 \\
\hline Stator resistance $[\Omega]$ & 2.21 \\
\hline
\end{tabular}

Table II

GEOMETRICAL DATA OF THE A-TYPE IPMSM MOTOR.

\begin{tabular}{c||c} 
Geometrical data & Value $[\mathrm{mm}]$ \\
\hline \hline External stator diameter & 81 \\
\hline Inner stator diameter & 49.6 \\
\hline External rotor diameter & 48 \\
\hline Inner rotor diameter & 18.46 \\
\hline Axial rotor length & 59 \\
\hline PM width & 13.45 \\
\hline PM thickness & 3 \\
\hline Air-gap & 0.8 \\
\hline Slot depth & 9.2 \\
\hline
\end{tabular}

in order to exploit the magnetic rotor saliency [8], increasing, therefore, the torque/weight ratio as high as possible.

Table III

IPMSM MAGNETIC AND GEOMETRIC CHARACTERISTICS

\begin{tabular}{c||c|c|c} 
Machine type & PM type & Air gap [mm] & PM mag. direction \\
\hline \hline A & SmCo & 0.8 & tangential \\
\hline B & NdFeB & 0.8 & tangential \\
\hline C & NdFeB & 0.4 & tangential \\
\hline D & SmCo & 0.8 & radial \\
\hline E & NdFeB & 0.8 & radial \\
\hline F & NdFeB & 0.4 & radial \\
\hline G & SmCo & 0.8 & mixed \\
\hline H & NdFeB & 0.8 & mixed \\
\hline I & NdFeB & 0.4 & mixed \\
\hline
\end{tabular}

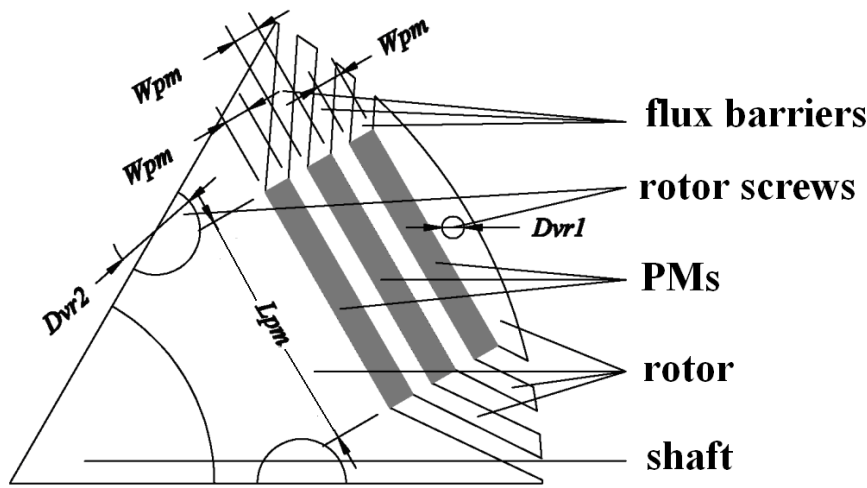

Figure 3. Angular section of the proposed D, E and F-type rotor structure.

This paper presents a study on torque/weight and torque/moment of inertia optimization for IPMSMs. More in detail, a comparison between several IPMSMs equipped with different rotor structures has been carried out in order to determine if the previously mentioned ratios can be maximized. This study starts from a commercial motor with known characteristics and it evolves in many prototypes by changing
Table IV

GEOMETRICAL PARAMETERS OF THE D-TYPE ROTOR STRUCTURE.

\begin{tabular}{c||c} 
Parameter & Value $[\mathrm{mm}]$ \\
\hline \hline PM1, PM2, PM3 width $L_{p m}$ & 11.2 \\
\hline PM1, PM2, PM3 thickness $W_{p m}$ & 1.2 \\
\hline
\end{tabular}

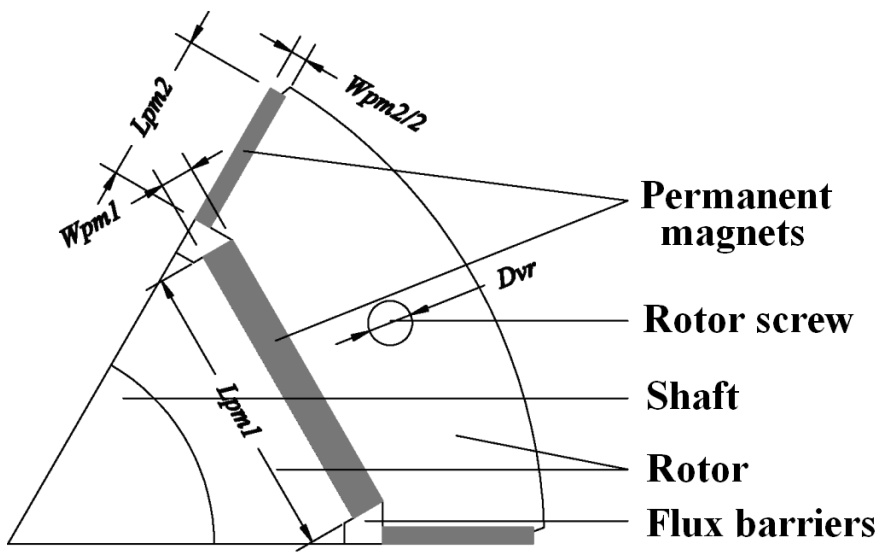

Figure 4. Angural section of the G, H and I-type rotor structure.

the rotor mechanical structure, maintaining the same stator configuration for each proposed prototype, as shown in Section II. Afterwards, a comparison between the different machines has been performed using a finite element method analysisbased software named FEMM, as described in Section III. The related FEM simulations have been carried out in order to evaluate the performance improvements of the machines due to the different IPMSM structures, by varying only the type of PM materials, the geometrical rotor structure and the PM orientation. From the comparison between the electrical and mechanical quantities of the proposed prototypes, especially from the torque/load angle characteristics comparison, significant performance improvements have been obtained as reported in Section IV.

\section{IPMSM PROPOSED STRUCTURES}

In this section nine rotor structures for IPMSMs are defined and reported, being them classified from a so called A-type structure to a I-type structure. More in detail, the differences between these structures can be identified by:

- the type of magnetization (tangential, radial or mixed);

- the type of PMs (SmCo or NdFeB);

- the dimension of the air-gap $(0.4 \mathrm{~mm}$ or $0.8 \mathrm{~mm})$.

For each structure, the same stator geometry is adopted, which allows to evaluate the IPMSM performances only in

Table V

GEOMETRICAL PARAMETERS OF THE G-TYPE ROTOR STRUCTURE.

\begin{tabular}{c||c} 
Parameter & Value $[\mathrm{mm}]$ \\
\hline \hline PM1 width $L_{p m 1}$ & 13.45 \\
\hline PM1 thickness $W_{p m 1}$ & 1.5 \\
\hline PM2 width $L_{p m 2}$ & 6.72 \\
\hline PM2 thickness $W_{p m 2}$ & 1.5 \\
\hline Screw holes diameter $D_{v r}$ & 2 \\
\hline
\end{tabular}




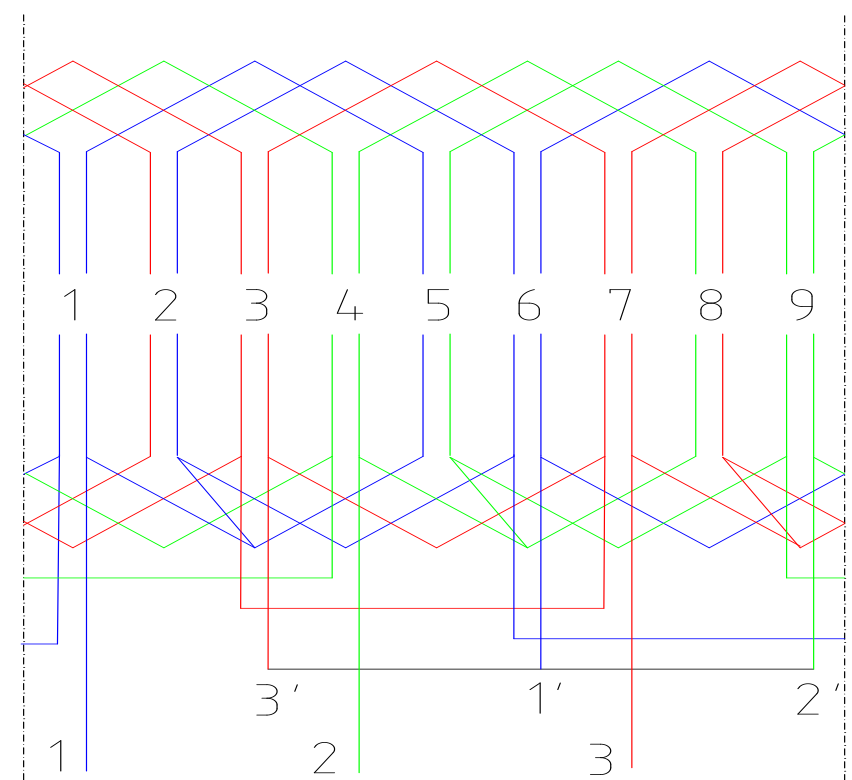

Figure 5. Base winding scheme of the three-phase IPMSMs (27 slots, 6 poles).

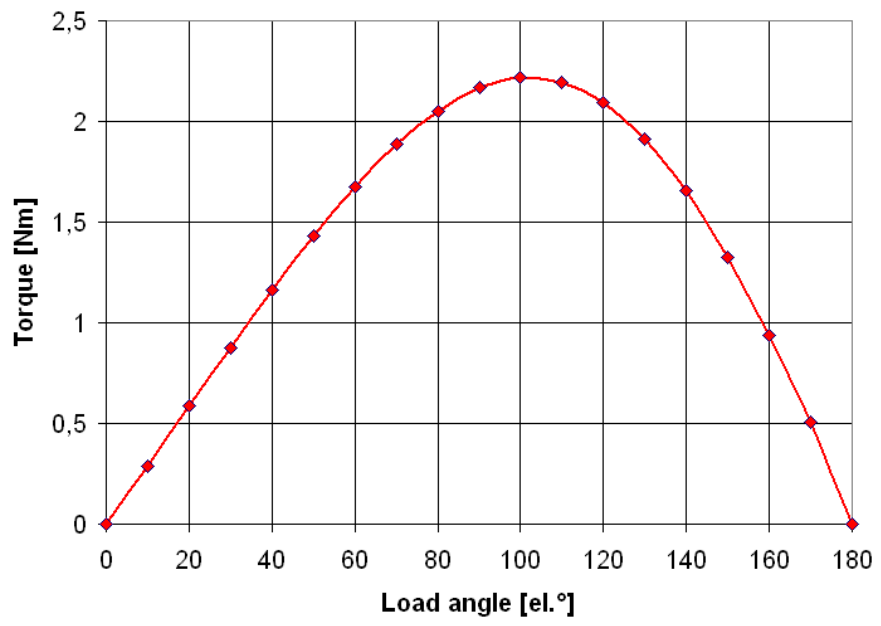

Figure 6. Torque/load angle characteristic for the A-type IPMSM.

dependence of the rotor structure. Table III summarizes the main characteristics that diversify the IPMSM machines.

The first IPMSM structure, named A-type, is shown in fig. 1. It is a six-pole brushless machine, whose SmCo PMs are radially mounted, but tangentially magnetized. The stator winding is a three-phase, double-layer fractional one, with a shortened pitch and is located into 27 slots. The number of slots per pole per phase is equal to 1.5. This structure has been carried out from a real machine (type BLQ-40, Magnetic S.r.l., Italy), shown in fig. 2 and whose rated values and geometrical data are reported in tables I and II, respectively. The stator and rotor cores are realized with iron laminates, whose magnetic permeability and electrical conductivity are equal to $\mu_{r}=14872$ and $\sigma=10.44 \mathrm{MS} / \mathrm{m}$, respectively. The PMs are produced by HITACHI inc. and are of the H-18B type (with a maximum specific energy $B H_{\max }=143 \mathrm{~kJ} / \mathrm{m}^{3}$ ).

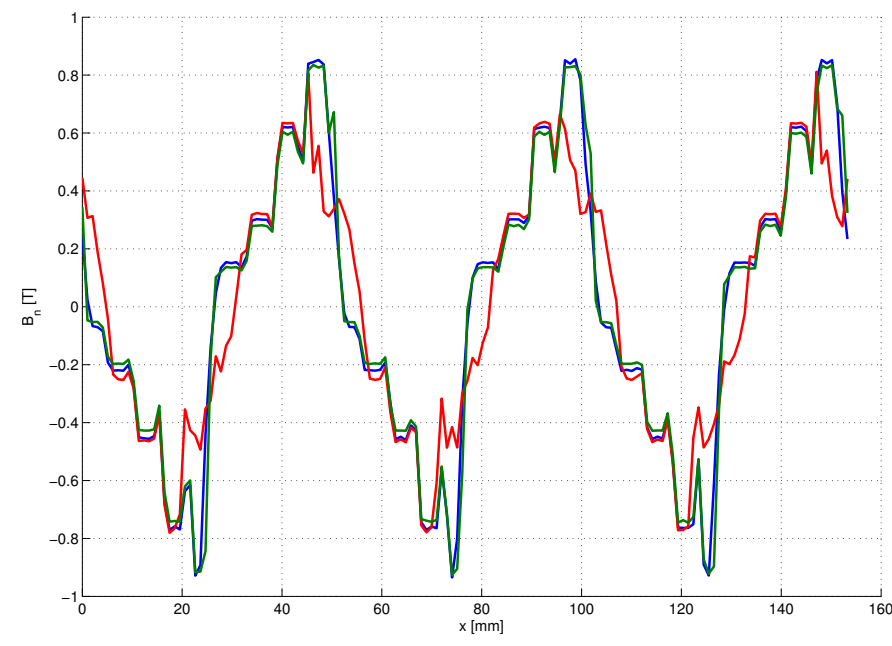

Figure 7. Radial component of the air gap flux density as a function of the position $\mathrm{x}$ for the A-type, D-type and G-type machines.

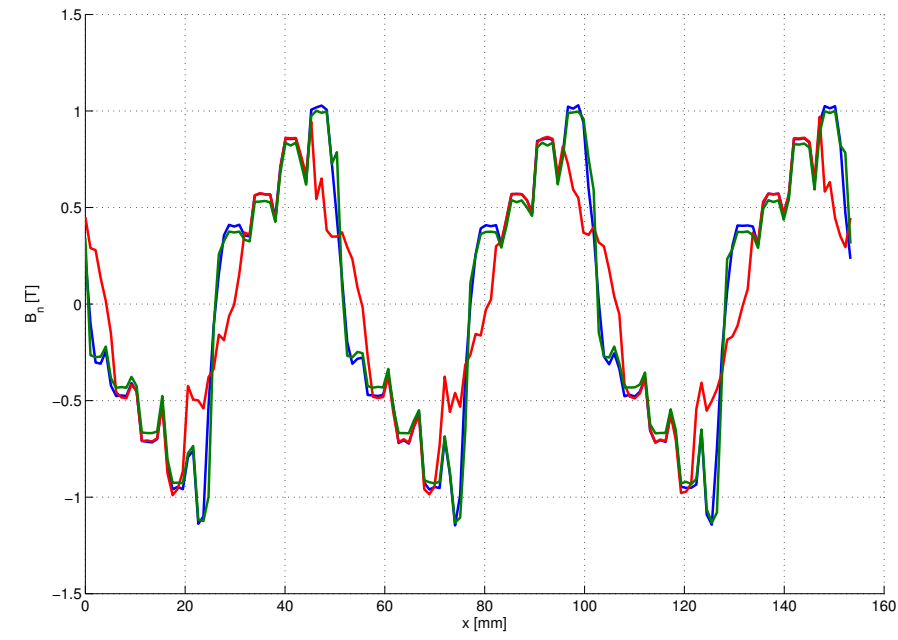

Figure 8. Radial component of the air gap flux density as a function of the position $\mathrm{x}$ for the B-type, E-type and H-type machines.

The B-type and C-type IPMSM models have been conceived with the same rotor structure of the A-type machine. However, the permanent magnets adopted for these prototypes are both composed by $\mathrm{NdFeB}\left(B H_{\max }=320 \mathrm{~kJ} / \mathrm{m}^{3}\right)$ and the air-gap dimensions are equal to $0.8 \mathrm{~mm}$ and $0.4 \mathrm{~mm}$, respectively.

The D-type model is composed by a PMa-SynRM (Permanent Magnet assisted Synchronous Reluctance Motor) rotor structure, whose angular cross-section is shown in fig. 3. The related geometrical parameters indicated in the figure are explained and summarized in table IV. Moreover, the magnetization of the permanent magnets is radially directed.

The E-type and F-type IPMSM models have been conceived with the same rotor structure of the D-type machine. However, the PMs adopted for these prototypes are both composed by $\mathrm{NdFeB}$ and the air-gap dimensions are equal to $0.8 \mathrm{~mm}$ and $0.4 \mathrm{~mm}$, respectively.

For the G-type, H-type and I-type models, the same stator structure of the six previously described models has been adopted. However, the permanent magnets are located in order to determine a direction of magnetization both radial and 

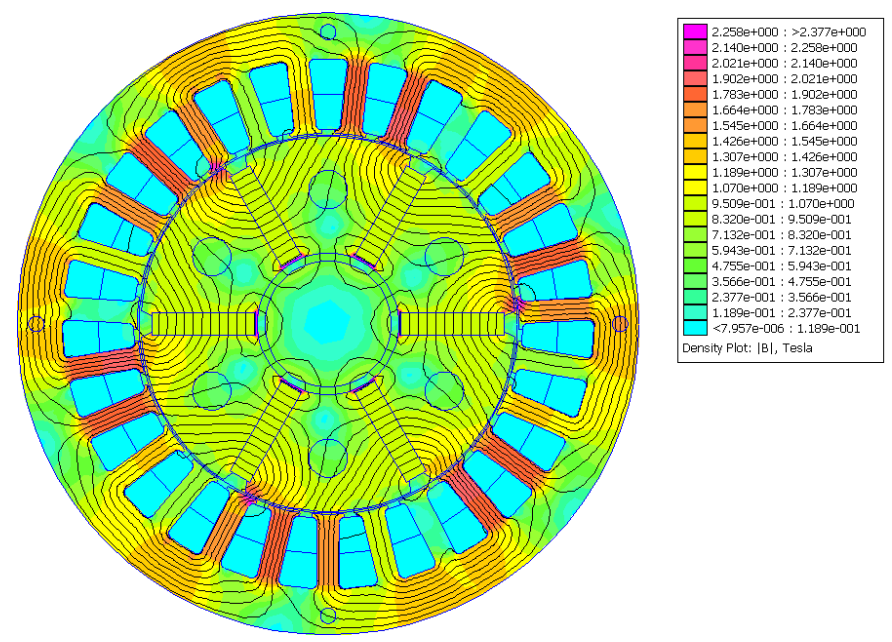

Figure 9. Density plot of the flux density field for the C-type structure.
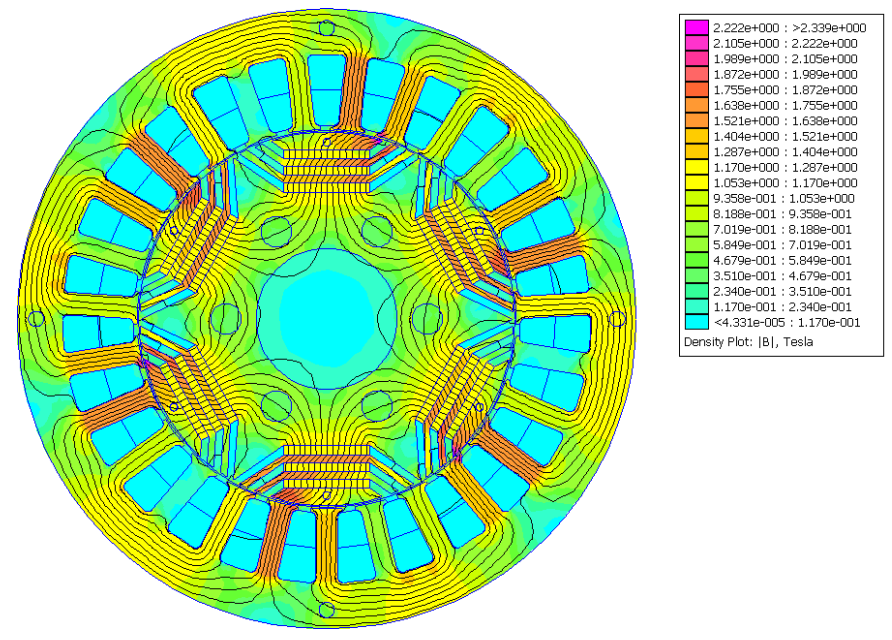

Figure 10. Density plot of the flux density field for the F-type structure.

tangential. An angular cross-section of the rotor is shown in fig. 4, while the related geometrical parameters indicated in the figure are explained and summarized in table V.

\section{FEM ANALYSIS OF THE IPMSM STRUCTURES}

The purpose of this work is to achieve the flux density field analysis of each type of the proposed IPMSM structures, in order to identify the configuration that improves their performances in terms of both torque/weight and torque/moment of inertia ratio increases.

In order to simplify this study, a FEM analysis has been preferred to traditional analytical methods. For this purpose the FEMM 4.2 software has been used. For the FEMM analisys, the three following process phases have been carried out:

1) pre-processing, which consists in the machine geometry definition and in the type of materials and in the related boundary conditions assignment.

2) solution, in which the FEM solution of the problem is determined and the flux density field values in the nodes of the finite elements are calculated.

3) post-processing, where the solutions in terms of scalar or vector quantities are analyzed, displayed and managed.
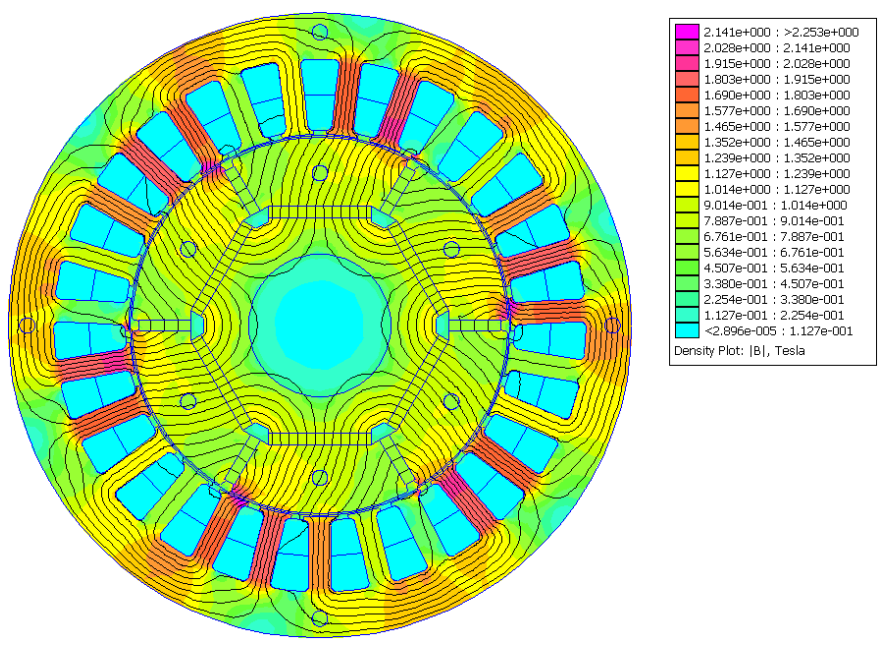

Figure 11. Density plot of the flux density field for the I-type structure.

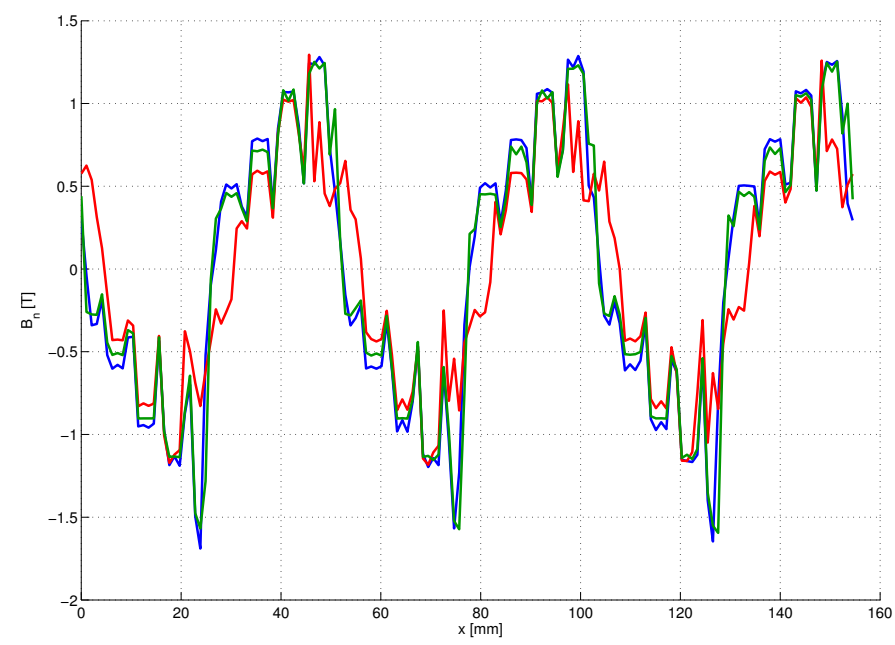

Figure 12. Radial component of the air gap flux density as a function of the position $\mathrm{x}$ for the B-type, E-type and H-type machines.

Within the post-process also the torque as a function of the load angle is determined by imposing the rotor rotation in steps of 10 electrical degrees (10/3 mechanical degrees) and calculating the related torque for each rotor angular position at a constant stator current.

In the first simulation, the A-type structure previously described has been analyzed. Figure 5 shows the base winding scheme of the proposed model, while fig. 6 shows the torque as a function of the load angle. The winding of the machine is determined by three series connected repetitions of the base winding shown in fig. 5 [13].

Moreover, the finite-element-method analysis has allowed to determine the flux density field distribution within the machine. Furthermore, the radial component of the flux density field as a function of the position $\mathrm{x}$, measured on the circumference passing through the middle of the air-gap, is reported in fig. 7 (blue line). In addition, the radial flux density values of the D-type and G-type models are reported and compared in the same figure.

The same procedure previously described has been adopted for all the proposed IPMSM models. More in detail, the radial 


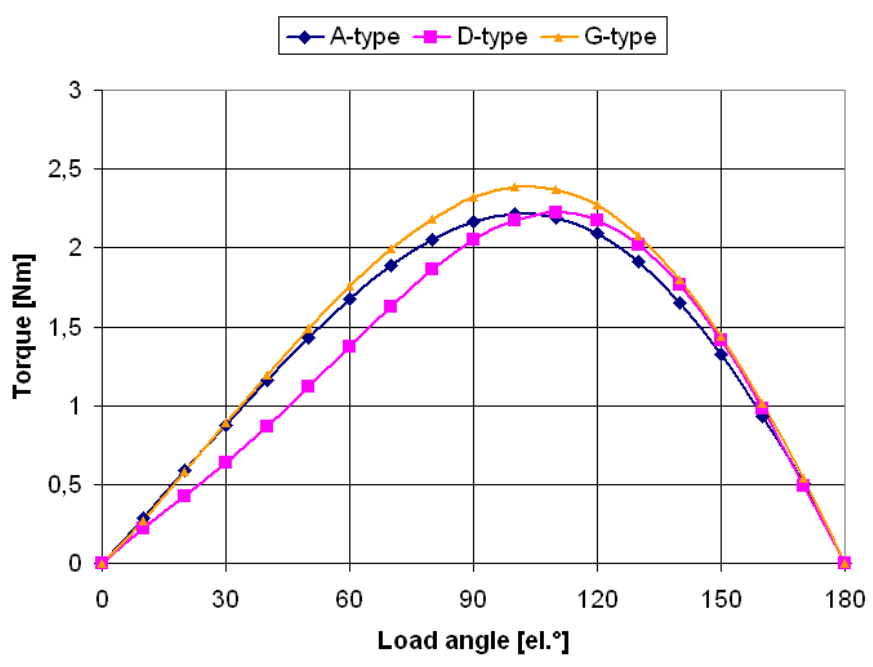

Figure 13. Comparison between the torque/load angle characteristics of the A-type, D-type and G-type IPMSMs.

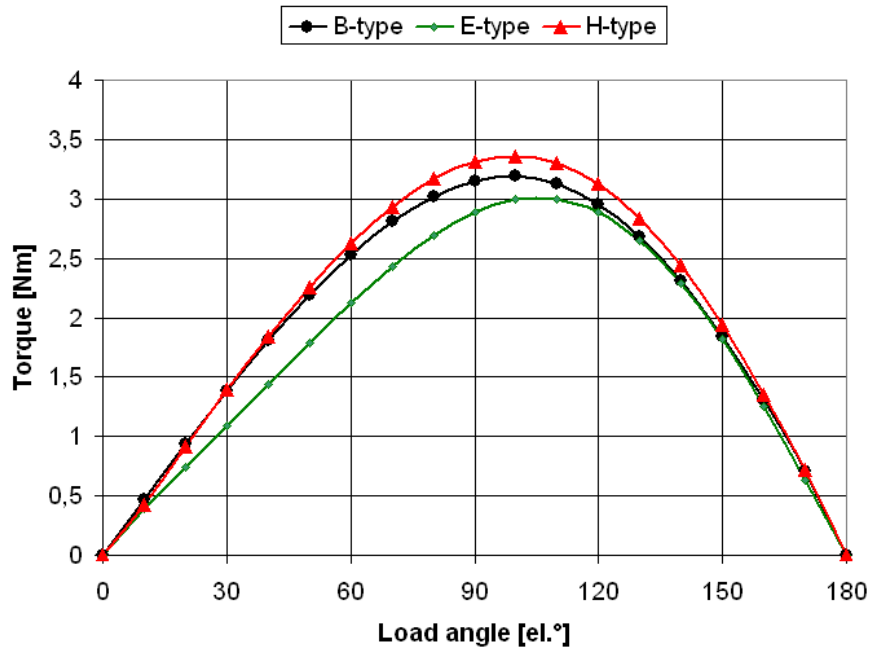

Figure 14. Comparison between the torque/load angle characteristics of the B-type, E-type and H-type IPMSMs.

component of the flux density as a function of the position $\mathrm{x}$, measured on the circumference passing through the middle of the air-gap, for the B-type model are reported in fig. 8 (blue line). In addition, the latter figure shows the comparison between the radial component of the flux density for the B-, E- and H-type structures.

Furthermore, the trends of the flux lines of the C-type, F-type and I-type are reported in figures 9, 10 and 11, respectively, while the radial component of the flux density as a function of the position $\mathrm{x}$ for the C-, F- and I-type models are all shown and compared in fig. 12. The FEM analysis previously described were carried out considering the armature current equal to the motor rated value (see table I).

\section{COMPARISON OF THE IPMSMS PERformances}

In order to compare the performances of the proposed IPMSM structures, the torque/load angle characteristics of each prototype have been determined and reported in the

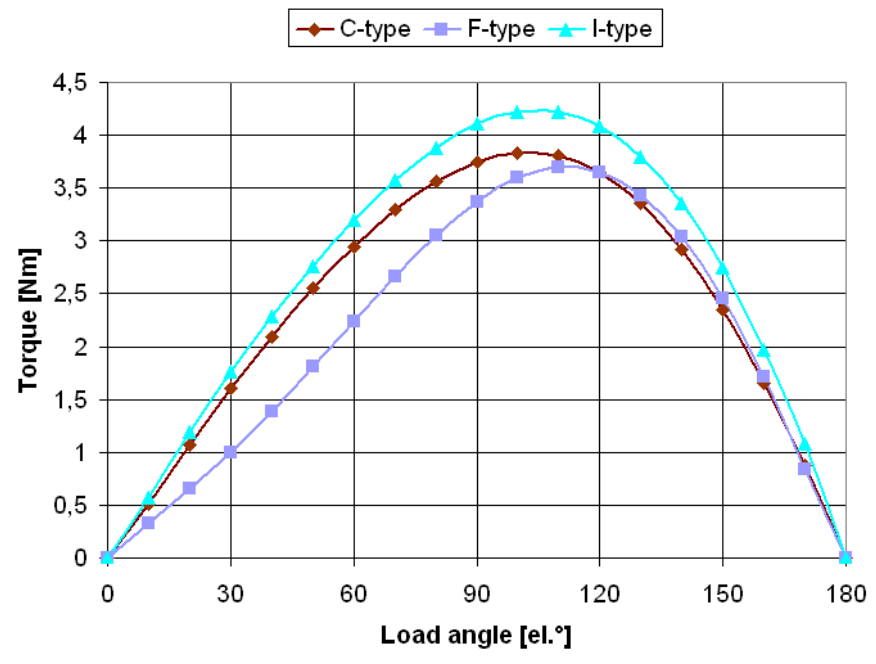

Figure 15. Comparison between the torque/load angle characteristics of the C-type, F-type and G-type IPMSMs.

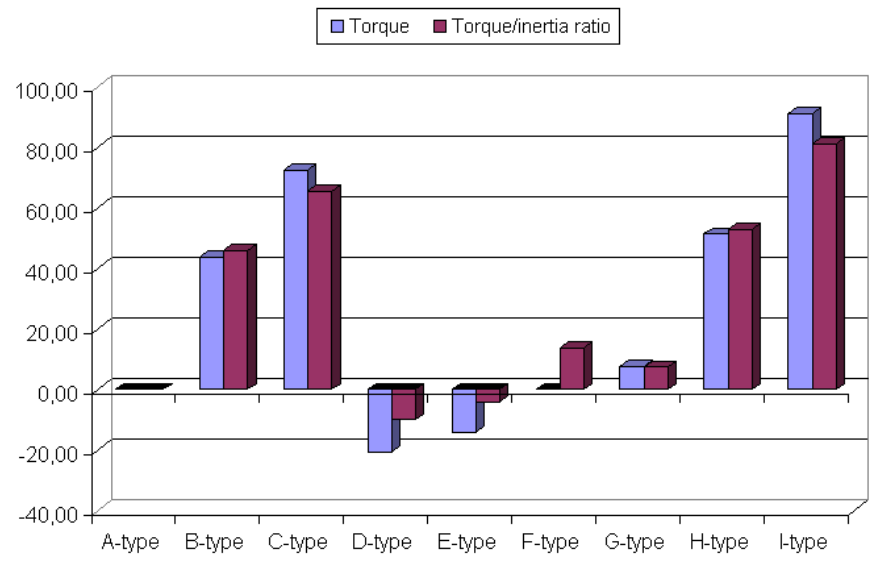

Figure 16. Torque/moment of inertia comparison for the proposed IPMSMs.

diagrams of figures 13,14 and 15. From the comparison, it appears evident that the improvement in terms of maximum achievable torque are obtained by selecting the geometry of fig. 4 ( $\mathrm{G}, \mathrm{H}$ and I-type geometry). However, the angular stability margin is increased with the structure chosen for the D, E, and F-type models. As it is possible to notice, the maximum torque value of each structure is obtained at different load angles $\theta_{x}$, ranging from $100^{\circ}$ to $112^{\circ}$. This is due to the magnetic saliency of the rotor, quantified by the ratio between direct and quadrature-axis inductances $\left(L_{d}\right.$ and $L_{q}$ ).

From the same graphs it appears evident that the best performances are achieved by a IPMSM with permanent magnets of $\mathrm{NdFeB}$ both radially and tangentially magnetized, with a $0.4 \mathrm{~mm}$ wide air gap. As a matter of fact, the torque $T_{x}$ is increased from $2.22 \mathrm{Nm}$, which is the maximum value achievable from the reference A-type model, to $4.24 \mathrm{Nm}$, obtained with the I-type structure. Furthermore, another great advantage is that the magnetic saliency is increased from 1.35 to 1.89 , as reported in table VI. However, the best performances in terms of saliency is achieved by the F-type 


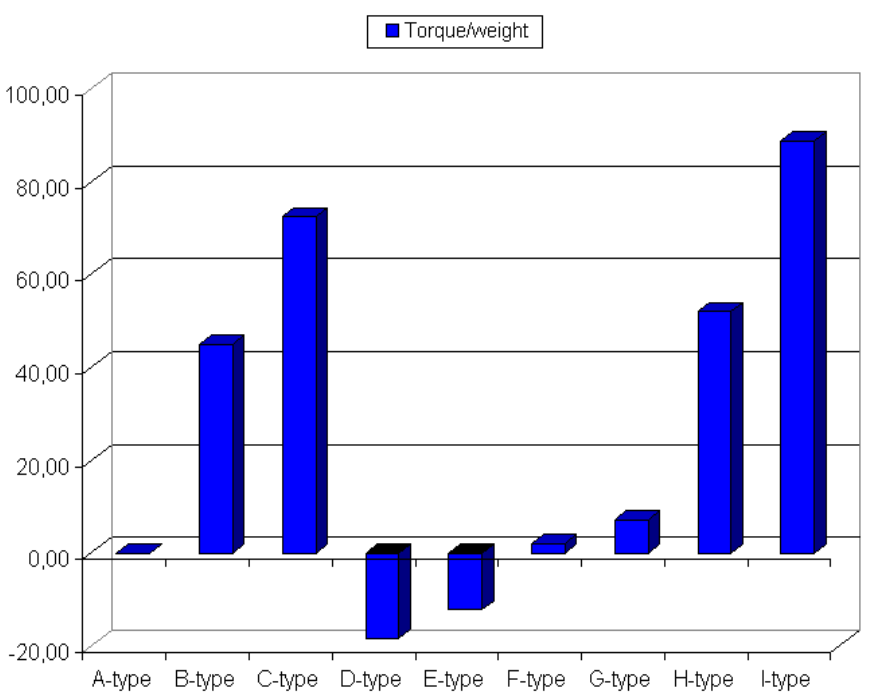

Figure 17. Torque/weight comparison of the proposed IPMSMs.

machine, which reaches the highest saliency ratio of 3.69, and for this reason this type of machine is characterized also by the highest angular stability margin.

The values of the torque and the torque/moment of inertia ratios with respect to the A-type reference structure are compared in the graph of fig. 16. It is possible to notice that the ratio between produced torque and the moment of inertia is maximized with the I-type IPMSM structure. Finally, the torque/weight values for the different proposed structures with respect to the A-type reference are shown in fig. 17. With the I-type model the torque/weight ratio has been optimized and increased from $0.98 \mathrm{Nm} / \mathrm{kg}$ to $1.69 \mathrm{Nm} / \mathrm{kg}$. In addition, there is also an economical advantage for the latter structure, due to the adoption of permanent magnets with reduced volumes and weight.

Table VI

IPMSM PERFORMANCE CHARACTERISTICS

\begin{tabular}{c||c|c|c|c|c} 
Type & $L_{d}[\mathrm{mH}]$ & $L_{q}[\mathrm{mH}]$ & $L_{d} / L_{q}$ & $\theta_{x}\left[\mathrm{el}^{\circ}{ }^{\circ}\right.$ & $T_{x}[\mathrm{Nm}]$ \\
\hline \hline $\mathrm{A}$ & 9.86 & 13.28 & 1.35 & 102 & 2.22 \\
\hline $\mathrm{B}$ & 9.86 & 13.28 & 1.35 & 100 & 3.19 \\
\hline $\mathrm{C}$ & 13.39 & 22.84 & 1.7 & 103 & 3.83 \\
\hline $\mathrm{D}$ & 5.03 & 12.89 & 2.56 & 110 & 2.22 \\
\hline $\mathrm{E}$ & 5.03 & 12.89 & 2.56 & 105 & 3.01 \\
\hline $\mathrm{F}$ & 5.93 & 21.86 & 3.69 & 112 & 3.70 \\
\hline $\mathrm{G}$ & 9.15 & 13.88 & 1.52 & 103 & 2.39 \\
\hline $\mathrm{H}$ & 9.15 & 13.88 & 1.52 & 100 & 3.36 \\
\hline $\mathrm{I}$ & 12.84 & 24.28 & 1.89 & 105 & 4.24 \\
\hline
\end{tabular}

\section{CONCLUSIONS}

In this paper a study on torque/weight and torque/moment of inertia optimization for IPMSMs has been presented. A comparison between several IPMSMs designed with nine different rotor structures has been carried out in order to determine which rotor geometrical characteristics affect the above mentioned ratios. The FEM analysis, carried out on each IPMSM model, has been performed in order to evaluate the performance of each machine. The torque/weight and torque/moment of inertia ratios were defined as performance indexes and were used in order to evaluate the related improvements. The different IPMSM structures were obtained by varying the type of PM materials, the geometrical rotor structure and the PM magnetization direction. From the comparison of the performance indexes, it can be stated that significant performance improvements can be obtained adopting a suitable rotor structure. In particular, with $\mathrm{NdFeB}$ PMs both radially and tangentially magnetized, the produced torque can be improved, while the angular stability margin can be improved by choosing PMs with radial magnetization (as for PMa-SynRM). Moreover, a reduction of the PM weight can be achieved without significant torque decrease and realizing cheaper machines.

\section{REFERENCES}

[1] W. Xu, J. G. Zhu, Y. Zhang, Z. Li, Y. Li, Y. Wang, Y. Guo, and Y. Li, "Equivalent circuits for single-sided linear induction motors," Industry Applications, IEEE Transactions on, vol. 46, pp. 2410-2423, Nov 2010.

[2] M. Caruso, V. Cecconi, A. Di Tommaso, and R. Rocha, "A flux and speed observer for sensorless spim applications," in Electrical Machines (ICEM), 2010 XIX International Conference on, pp. 1-6, Sept 2010.

[3] M. Caruso, V. Cecconi, A. O. Di Tommaso, and R. Rocha, "A Rotor Flux and Speed Observer for Sensorless Single-Phase Induction Motor Applications," International Journal of Rotating Machinery, vol. 2012, no. 276906, p. 13, 2012.

[4] M. Caruso, V. Cecconi, A. O. Di Tommaso, and R. Rocha, "Sensorless variable speed single-phase induction motor drive system based on direct rotor flux orientation," in Electrical Machines (ICEM), 2012 XXth International Conference on, pp. 1062-1068, Sept 2012.

[5] M. Caruso, V. Cecconi, A. O. Di Tommaso, and R. Rocha, "Sensorless variable speed single-phase induction motor drive system," in Industrial Technology (ICIT), 2012 IEEE International Conference on, pp. 731736, March 2012.

[6] N. Ghalichechian, A. Modafe, M. Beyaz, and R. Ghodssi, "A rotary micromotor supported on microball bearings," in Solid-State Sensors, Actuators and Microsystems Conference, 2007. TRANSDUCERS 2007. International, pp. 1123-1126, June 2007.

[7] M. Caruso, "Modeling and simulation of a vcm micromotor and its potential applications," in AEIT Annual Conference, 2013, pp. 1-6, Oct 2013.

[8] A. O. Di Tommaso, G. Ricco Galluzzo, and R. Miceli, "Improvement of IPMSM Performance through a Mixed Radial-tangential Rotor Structure," in IEEE International Symposium on Industrial Electronics (ISIE), (Bari, Italy), pp. 1327-1332, IEEE, 2010.

[9] A. Sorgdrager and A. Grobler, "Influence of magnet size and rotor topology on the air-gap flux density of a radial flux pmsm," in Industrial Technology (ICIT), 2013 IEEE International Conference on, pp. 337343, Feb 2013.

[10] A. O. Di Tommaso, R. Miceli, G. Ricco Galluzzo, and M. Trapanese, "Efficiency maximization of permanent magnet synchronous generators coupled coupled to wind turbines," in Power Electronics Specialists Conference, 2007. PESC 2007. IEEE, pp. 1267-1272, June 2007.

[11] A. Di Tommaso, F. Genduso, R. Miceli, and G. Galluzzo, "Computer aided optimization via simulation tools of energy generation systems with universal small wind turbines," in Power Electronics for Distributed Generation Systems (PEDG), 2012 3rd IEEE International Symposium on, pp. 570-577, June 2012.

[12] A. O. Di Tommaso, F. Genduso, and R. Miceli, "A software for the evaluation of winding factor harmonic distribution in high efficiency electrical motors and generators," in 2013 8th International Conference and Exhibition on Ecological Vehicles and Renewable Energies (EVER), pp. 1-6, March 2013.

[13] A. O. Di Tommaso, F. Genduso, R. Miceli, and C. Spataro, "Assisted Software Design of a Wide Variety of Windings in Rotating Electrical Machinery," in 2014 9th International Conference and Exhibition on Ecological Vehicles and Renewable Energies (EVER), pp. 1-6, March 2014. 